\title{
Surface strain anomaly induced by the storage and drainage of englacial water in Koryto glacier, Kamchatka, Russia
}

\author{
Shin SUGIYAMA, ${ }^{1}$ Renji NARUSE, ${ }^{2}$ Yaroslav D. MURAV'YEV ${ }^{3}$ \\ ${ }^{1}$ Laboratory of Hydraulics, Hydrology and Glaciology, ETH-Zentrum, CH-8092 Zürich, Switzerland \\ E-mail:sugiyama@vaw.baug.ethz.ch \\ ${ }^{2}$ Institute of Low Temperature Science, Hokkaido University, Sapporo 060-0819, Japan \\ ${ }^{3}$ Institute of Volcanology, Russian Academy of Sciences, 9 Piip Boulevard, 683006 Petropavlovsk-Kamchatsky, Russia
}

\begin{abstract}
To investigate short-term flow-pattern variations of a temperate glacier, longitudinal surface strain was measured with a wire strainmeter in the ablation area of Koryto glacier, Kamchatka, Russia. Strain-rate anomalies were observed in late summer 2000 that were triggered by a water overflow from a moulin near the measurement site followed by the drainage of accumulated water. The strain event started with (compressive) strain rates of $>-10^{-3} \mathrm{~d}^{-1}$ lasting for 6 hours, which then became tensile. Similar strain-rate variations were observed again on the next day. During the event, basal sliding speed measured at the margin in the lower reach of the glacier fluctuated by about $\pm 50 \%$ of the daily mean. Smaller and larger sliding speeds corresponded to the compressive and tensile surface strains, respectively. These measurements suggest that the storage and sudden drainage of water caused spatially non-uniform water-pressure fluctuations along the glacier, changing the sliding regime over short time periods.
\end{abstract}

\section{INTRODUCTION}

The flow speed of a temperate glacier fluctuates under the influence of basal conditions. Because subglacial water plays an important role in basal flow processes, short-term flow variations are often induced by changes in water input caused by an intensive melt event (e.g. Iken and others, 1983; Naruse and others, 1992; Mair and others, 2001), diurnal meltwater production (e.g. Iken and Bindschadler, 1986; Sugiyama and Gudmundsson, 2003), heavy rainfall (e.g. Jansson and Hooke, 1989; Gudmundsson and others, 2000) and drainage of a glacial lake (e.g. Nolan and Echelmeyer, 1999).

To study the response of a glacier to short-term variations in water input, high-frequency ice-flow measurements are required. Automatic operation of a distance meter (Hanson and others, 1998), theodolite (Gudmundsson and others, 2000) and global positioning system (Gudmundsson, 2002) have been used for surface flow speed measurements with
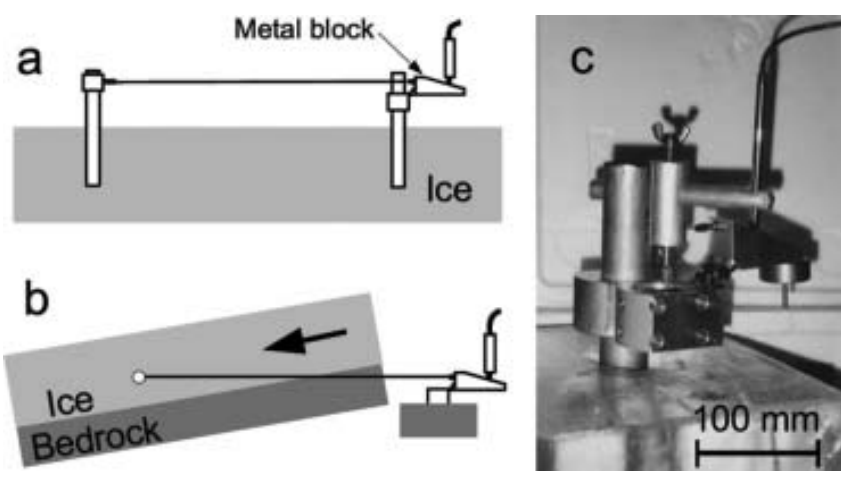

Fig. 1. (a, b) Schematic diagrams showing the installation of the wire strainmeter for (a) surface strain and (b) marginal sliding measurements. (c) The key component of the strainmeter which measures the tilt of the metal block with the displacement transducer. intervals of hours or less. Alternatively, surface strain has been measured on several glaciers with specially prepared strainmeters (Raymond and Malone, 1986; Jansson and Hooke, 1989). Raymond and Malone (1986) installed several strainmeters on Variegated Glacier, Alaska, USA, and observed propagation of strain anomalies during fastflow events.

We operated a wire strainmeter on a temperate valley glacier in Kamchatka, Russia, and used the same apparatus to measure marginal sliding speed. This paper reports the observations of surface strain anomalies and sliding-speed variations induced by water stored in the glacier. Results reveal the influence of non-uniformly distributed subglacial water pressures on the flow regime of the glacier.

\section{MEASUREMENT APPARATUS}

The wire strainmeter constructed for this study was similar to that used on Variegated Glacier (Raymond and Malone, 1986). Changes in the distance between two metal poles (36 $\mathrm{mm}$ diameter, $1 \mathrm{~m}$ long) installed on the glacier were measured using a Super Invar wire $(0.25 \mathrm{~mm}$ diameter $)$. One end of the wire was fixed to one of the poles, while the other end was connected to a metal block balanced with a pivot on the second pole (Fig. 1a). The metal block tilts when the glacier surface strains, and the tilt was sensed by a displacement transducer (Keyence AT3-001) placed in contact with the block. Direct-current output from the transducer was recorded every minute with a datalogger (Hioki 3635-05) with a resolution of $10^{-3} \mathrm{~mm}$, corresponding to a strain of $10^{-6}$ when the poles were installed $1 \mathrm{~m}$ apart.

The apparatus was tested in a cold room by measuring the thermal strain of an ice block $(1000 \times 500 \times 250 \mathrm{~mm})$ between two poles installed $600 \mathrm{~mm}$ apart. Because the thermal expansion coefficient of Super Invar $\left(10^{-6} \mathrm{~K}^{-1}\right)$ is about $2 \%$ of that for ice, the influence of thermal stretching of the wire was neglected. To evaluate the measurement result, the thermal strain caused by temperature changes in 


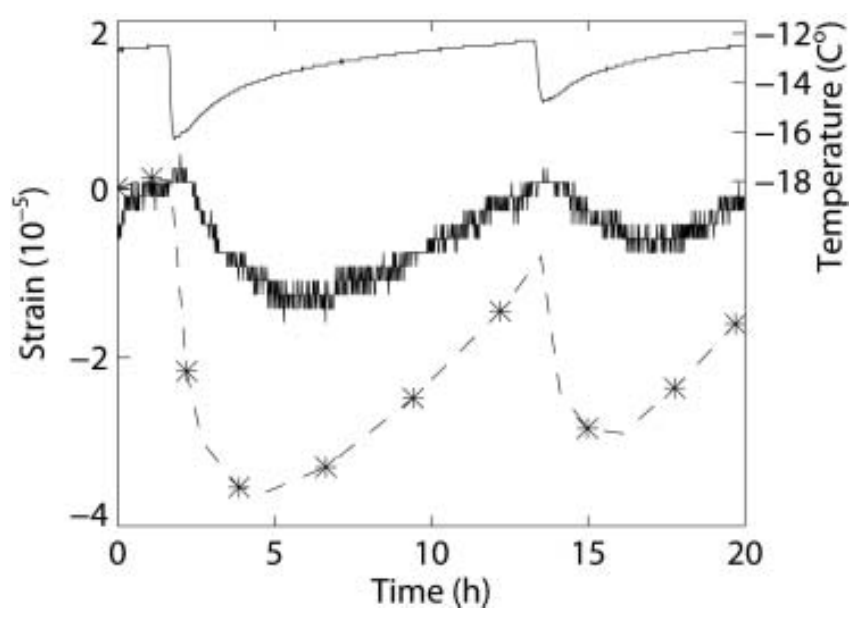

Fig. 2. Air temperature in the cold room (top line), and measured (middle line) and computed (bottom line) strain of the ice block. The computational results are indicated by the asterisks, and the dashed line is drawn arbitrarily.

the cold room was computed with finite-element commercial software ANSYS. The model solves a transient thermomechanical problem in a vertical cross-section along the measurement axis. Figure 2 shows air temperature and the measured and computed strain, taking tensile strain as positive. Although the magnitude of the measured strain is smaller than the model result, the timing of the compression due to the drop in temperature and the subsequent transition from compressive to tensile strain rate were consistent between measured and modelled results. Considering the simplification introduced in the finite-element modelling, arising for example from the model's two-dimensional nature and simplified boundary conditions, the accuracy of the strainmeter was difficult to assess. It is possible that the instrument did not fully respond to the strain because of its mechanical play. Nevertheless, the test result confirmed the potential of the apparatus to measure changes in strain with a magnitude of $10^{-5}$, and we focus more on the timing and the sign of the strain measured in the field rather than its magnitude.

\section{FIELD MEASUREMENTS \\ Study site}

Koryto glacier is a temperate valley glacier located on the east coast of Kamchatka peninsula, ranging in altitude between 320 and $1200 \mathrm{~m}$ (Fig. 3). It is a maritime glacier characterized by large winter accumulation ( $>7 \mathrm{~m}$ w.e. near the top) and summer ablation ( $>7 \mathrm{~m}$ w.e. near the terminus) (Shiraiwa and others, 1997). During the ablation season, the surface flow speed varies under the influence of meltwater and precipitation, suggesting that basal motion plays an important role in the dynamics of this glacier (Yamaguchi and others, 2003).

\section{Surface strain measurement}

From early August to mid-September 2000, surface strain was measured with wire strainmeters at several locations in the ablation area. For most of the measurement period, it was necessary to reinstall the strainmeters every 2-3 days due to large melting rates reaching $100 \mathrm{~mm}$ w.e. $\mathrm{d}^{-1}$. The data presented here were obtained at site KK4 (Fig. 3)

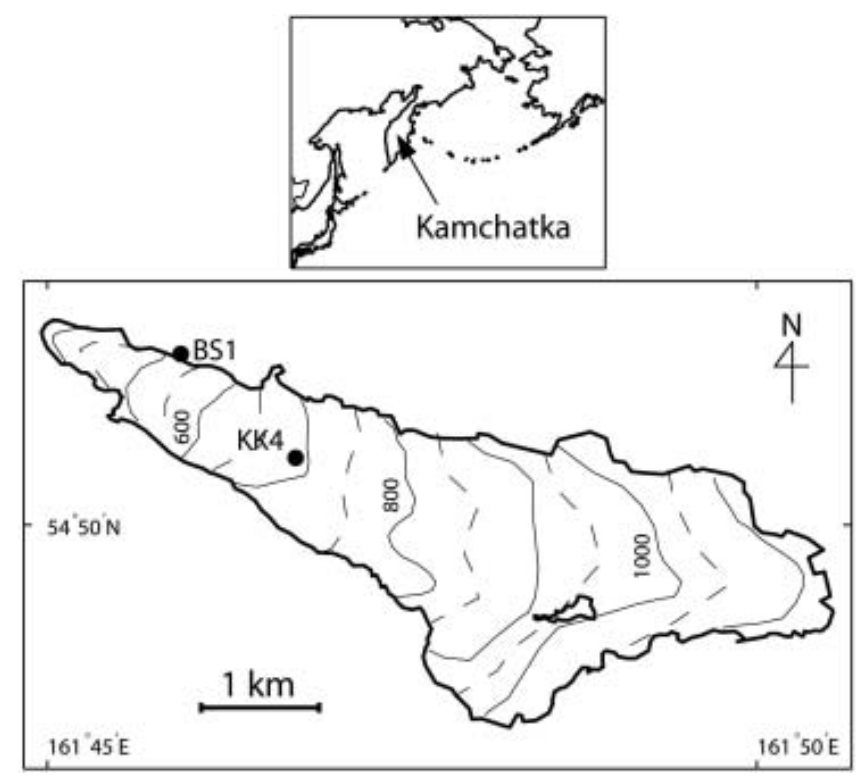

Fig. 3. Map of Koryto glacier showing the locations of the surface strain (KK4) and marginal sliding (BS1) measurements. Contour lines indicate the surface elevation in $\mathrm{m}$ a.s.l.

from 27 to 30 August with poles installed $1.5 \mathrm{~m}$ apart along the flowline. During this period, the measurement was continuous without reinstallation owing to a relatively low melt rate of $33 \mathrm{~mm}$ w.e. $\mathrm{d}^{-1}$, and a lack of precipitation.

\section{Basal sliding measurement}

The wire strainmeter was also utilized for the measurement of basal sliding at the glacier margin. Instead of using two poles, one end of the wire was anchored on the side of the glacier in basal ice with an ice screw, and the metal block was balanced with a pivot which was fixed on bedrock (Fig. 1b).

Sliding was measured from late August to mid-September at site BS1 (Fig. 3). We were able to reach a point along the glacier margin where 10-20 m thick ice was sliding over bedrock with no underlying sediment. Data from the wire meter were obtained intermittently, as they were interrupted by both melting out of the ice screw and failures of the battery. Although the exact direction of the glacier sliding was not known, the wire was likely not parallel to the ice motion. Displacement measured by the apparatus therefore represents an unknown but likely steady fraction of the three-dimensional movement of the basal ice. However, here we call the rate of the measured displacement simply 'sliding speed'.

\section{Observation of a moulin at KK4}

About $30 \mathrm{~m}$ up-glacier from the surface strain measurement site, one of the largest moulins of the glacier collected meltwater produced in the region. Several shafts in a healed crevasse were enlarged by water flow and had developed to a 1-2 $\mathrm{m}$ wide, $20 \mathrm{~m}$ long water inlet in summer 2000. A series of inactive moulins were found down-glacier along the flowline with intervals of about $50 \mathrm{~m}$, suggesting that the moulins were formed annually at the same location.

On 28 August at $1930 \mathrm{~h}$, we observed the moulin completely filled with water and overflowing onto the glacier surface for the first time (Fig. 4a). By the next day at $1400 \mathrm{~h}$, water stored in the moulin had already drained 

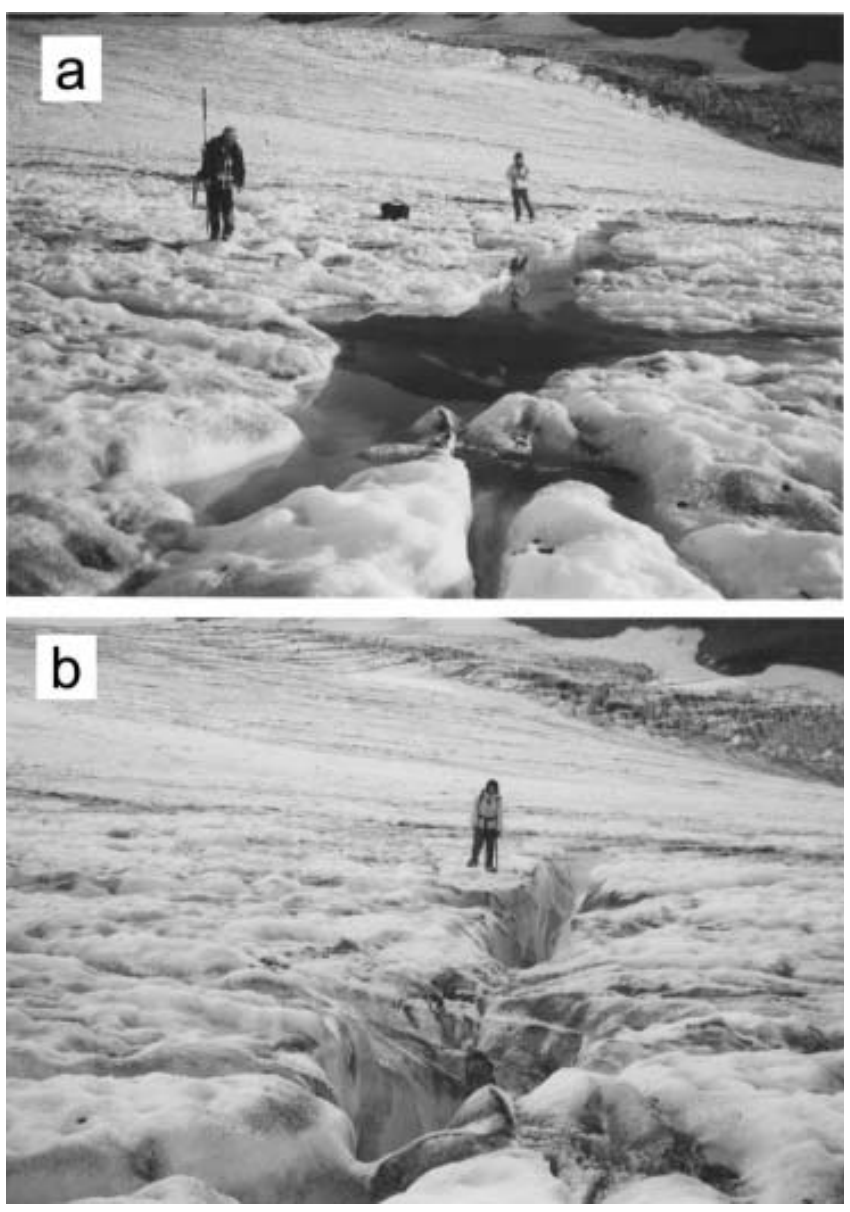

Fig. 4. The moulin at KK4 filled with water at $1930 \mathrm{~h}$ on 28 August (a), and under normal conditions at $1400 \mathrm{~h}$ on 29 August (b). Photographs are taken looking south.

(Fig. 4b), but similar events, called 'overflow' hereafter, were observed several times in September.

\section{RESULTS}

Longitudinal surface strain measured at KK4 is shown in Figure 5. From 27 to 28 August, before the first observation of moulin overflow, the mean tensile strain rate was $1.4 \times 10^{-5} \mathrm{~d}^{-1}$ which is in good agreement with the value of $2.1 \times 10^{-5} \mathrm{~d}^{-1}$ determined by repeated theodolite surveys of stakes installed $100 \mathrm{~m}$ apart from each other for the period 26 August-10 September. On the afternoon of 28 August, a sudden (compressive) strain reaching $-5 \times 10^{-4}$ followed by a similar amount of extension was recorded. This incident coincided with the overflow of the moulin. Another strain event took place at noon on 29 August. Although we did not observe that the moulin was filled with water on 29 August, this does not mean an overflow did not occur. Inspections were only made once or twice a day, as we passed by the location.

On 29 August when the large strain was observed, downglacier basal sliding showed fluctuations (Fig. 6). Displacement of the basal ice relative to the bedrock at BS1 and its rate (sliding speed) are shown in Figure 6 together with the surface strain and strain rate at KK4. Sliding speed and strain rate were calculated after smoothing the raw displacement and strain data with the kernel regression method (Brockmann and others, 1993). The sliding speed at BS1 and the

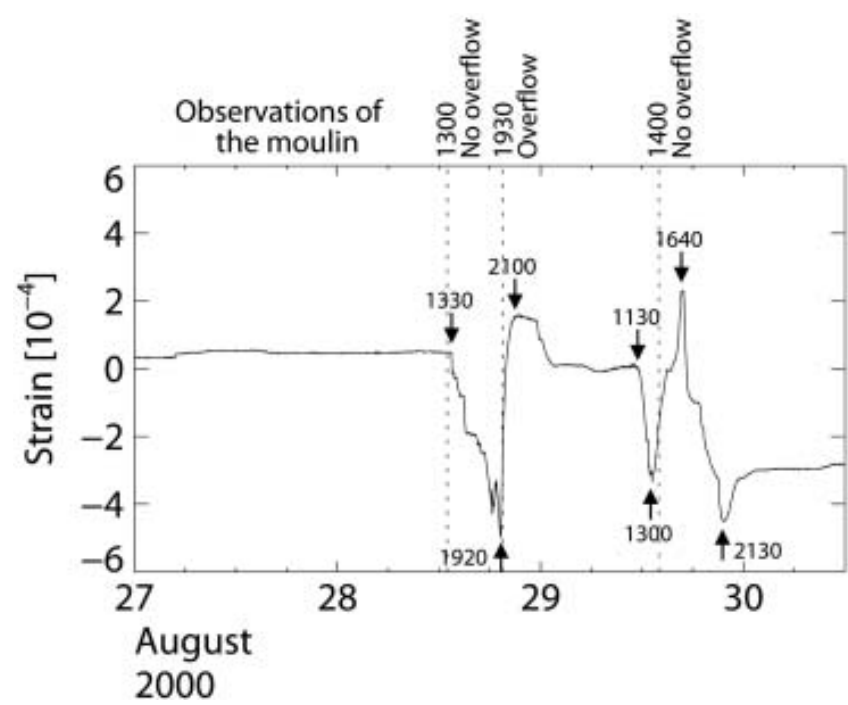

Fig. 5. Surface strain at KK4 obtained with a wire strainmeter. Times of drastic changes in the strain are indicated, and observed conditions of the moulin are described at the top.

strain rate at KK4 are well correlated: lower and higher sliding speeds correspond to compressive and tensile strain rate, respectively. The amplitude of the sliding-speed variations is about $50 \%$ of the mean value.

\section{DISCUSSION}

The coincidence of the strain event with the overflow of the moulin on 28 August suggests that extraordinary subglacial hydraulic conditions caused the changes in the ice-flow regime. We propose the following interpretation of the anomalous longitudinal strain variations. When a subglacial conduit constricted, meltwater started to fill the moulin, resulting in a reduction in basal water transport to the lower reaches of the glacier. Due to the changes in water pressure, ice-flow speed increased up-glacier and decreased in the lower glacier, inducing a compressive longitudinal strain rate at KK4 (Fig. 7b). When the conduit regrew, the large amount of water that was stored in the moulin and nearby subglacial drainage system drained down-glacier. Flow speed then increased in the lower reaches and the strain became tensile (Fig. 7c). The above interpretation explains why the strain events started with longitudinal compression and then turned to extension. It also agrees with the observation that lower and higher sliding speeds at BS1 corresponded to compressive and tensile surface strain rates at KK4. For the event on 29 August, it is plausible that the conduit constricted again at $1640 \mathrm{~h}$, and then opened at 2130 h (Fig. 5).

It is likely that some of the subglacial drainage conduits closed because of insufficient conduit water pressure in the late ablation season. The timing of the events, which started around noon and ended in the evening, implies that the constriction and regrowth of the conduits were controlled by meltwater supply to the bed. Subglacial conduits became narrower during the night, when water pressure was low. Then the strain events occurred as meltwater supply increased and exceeded the subglacial drainage capacity. The conduits were enlarged toward the evening due to high water flow and subglacial water pressure until the stored water was drained. Hourly discharge measured at the outlet 

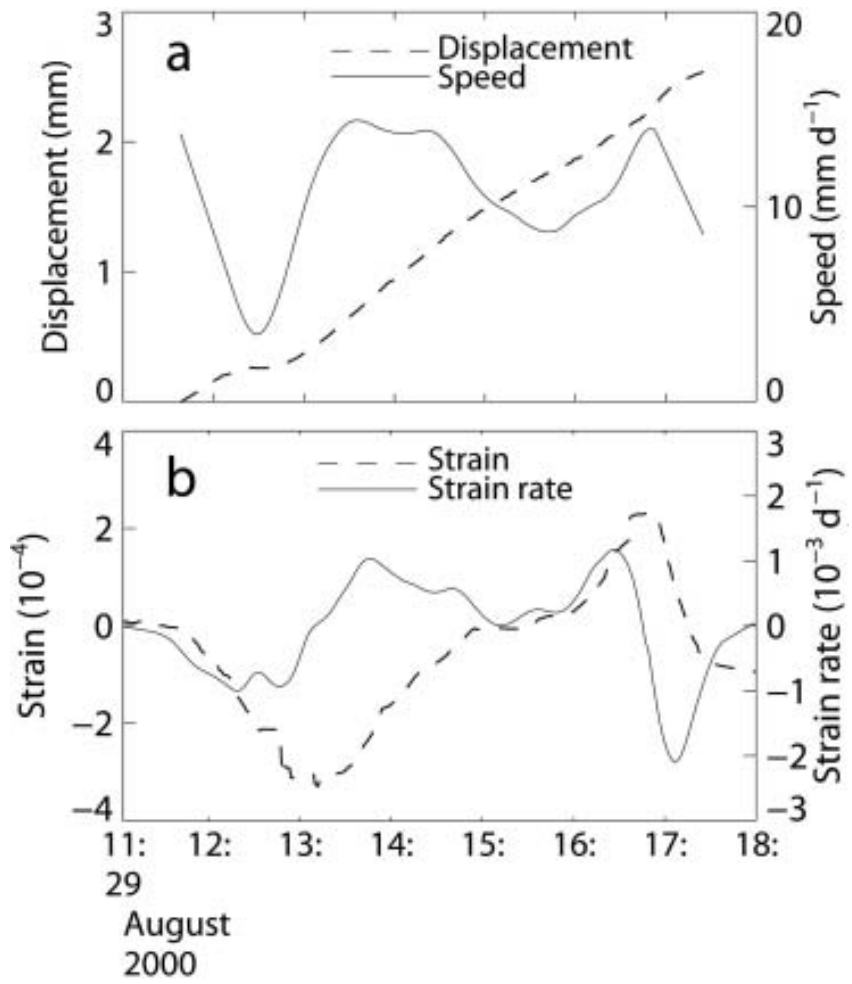

Fig. 6. Comparison of sliding at BS1 and strain at KK4 from 1100 to $1800 \mathrm{~h}$ on 29 August. (a) Displacement of the basal ice relative to bedrock (dashed line) and sliding speed (solid line). (b) Surface strain (dashed line) and strain rate (solid line).

stream (Matsumoto and others, 2004) was examined to find a trace of the drainage events, but significant peaks were not observed. Because the drainage of the moulin occurred in the late afternoon, it was presumably obscured by the daily discharge maximum.

The significant response of surface strain suggested that water was stored over an area broad enough to set up a gradient in the sliding field. The length scale over which water is expected to be stored is more than a few times the ice thickness (Kamb and Echelmeyer, 1986), which is about $200 \mathrm{~m}$ at KK4 (personal communication from Yu. Macheret, 2001). If the same quantity of water were stored for longer periods of time, until the following summer, for example, it would not only affect seasonal flow-speed variations but also would impact the water budget of the glacier. That substantial water was stored within and under Koryto glacier before the ablation season is suggested by other studies. Run-off and ablation measurements in Koryto glacier showed a $9 \times 10^{6} \mathrm{~m}^{3}$ water deficit from August to September 2000 (Matsumoto and others, 2004). Vertical surface movement during the same period was downward over most of the glacier, implying that a large amount of water was stored in basal cavities in the early summer (Yamaguchi and others, 2003).

The observed strain events reported here indicated a significant impact of changing subglacial conditions on glacier dynamics. Basal water pressure locally exceeded the ice overburden pressure when the moulin was filled with water, so the ice was considered to be decoupled from the bed. Presumably, discharge of the stored water enhanced basal motion in the lower reach of the glacier by increasing water pressure there. Such processes can be compared to the

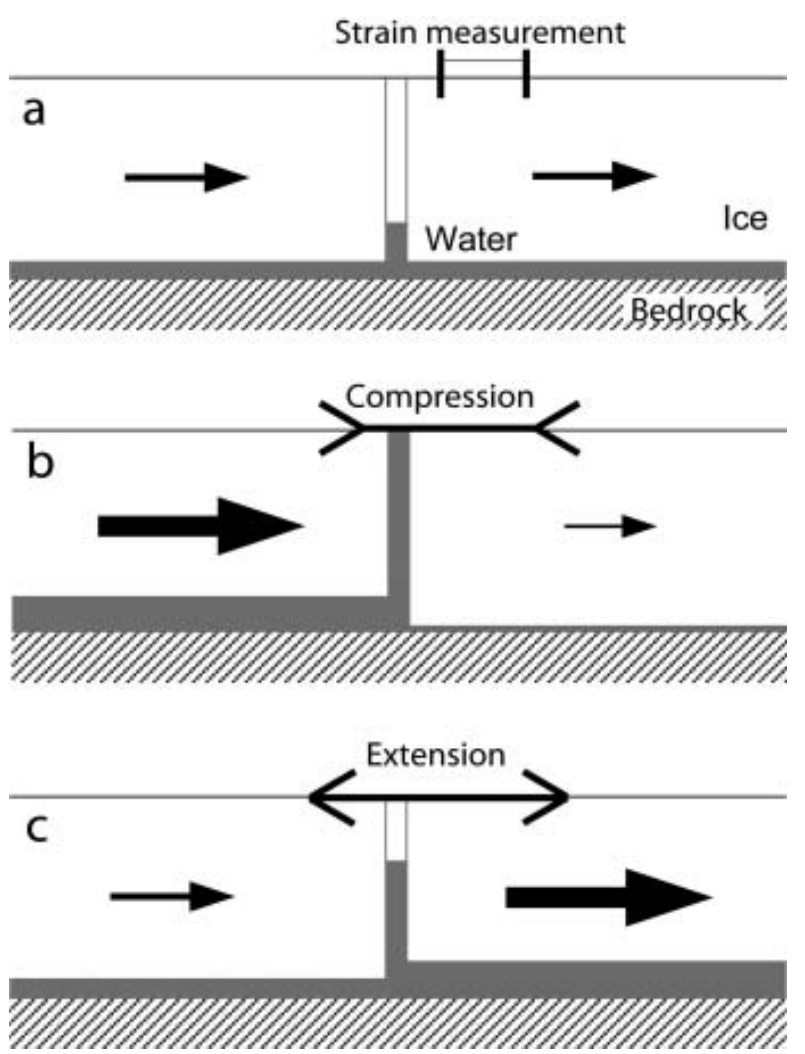

Fig. 7. Schematic diagrams of a longitudinal cross-section of the glacier showing subglacial water conditions and ice-flow regimes. (a) Normal conditions. (b) Moulin overflow. (c) Moulin drainage.

formation and rapid drainage of a glacier-dammed lake. On Black Rapids Glacier, Alaska, USA, drainage of marginal and supraglacial lakes increased the surface flow speed by up to $400 \%$ (Nolan and Echelmeyer, 1999) and also caused vertical straining in the ice near the surface (Raymond and others, 1995).

Sliding-speed variations at glacier margins may not directly represent the changes in basal motion in the central area. Nevertheless, the correlation found between the sliding speed at BS1 and the strain rate at KK4 implies that the marginal sliding was enhanced when the glacier bed was pressurized by the drainage of water stored up-glacier. A possible effect of such subglacial conditions on sliding at the margin is basal shear stress transfer from the center to the margins. Reduction in the basal traction in the center of the glacier causes increases in the shear stress near the sidewalls, resulting in enhanced sliding at the margins. Glen and Lewis (1961) measured the movement of ice at the side of Austerdalsbreen, Norway, and found greater sliding speeds during periods of heavy rainfall or high temperature. Although regional conditions such as bedrock irregularities, boulders in basal ice, or melting at the bed should also be considered, the increase in marginal sliding can be understood as a consequence of shear stress transfer to the margins.

\section{CONCLUSION}

The cold-room test of the wire strainmeter and the operation in the field demonstrated its ability to measure short-term flow variations with a time-scale of $<1$ hour. It is a unique tool for investigation of both glacier dynamics and laboratory ice mechanics with a high temporal resolution. 
The strainmeters were used to measure surface strain and marginal sliding of a temperate glacier with a temporal resolution of $1 \mathrm{~min}$. The measurements captured the response of the glacier to the overflow and subsequent draining of a large moulin during the late ablation season. We suggest that subglacial water pressure was nonuniformly distributed during the overflow and the subsequent drainage of the stored water. The observation revealed the influence of short-term local changes in water input on the glacier flow regime, providing insight into the likely effects of glacier outburst floods on glacier dynamics.

\section{ACKNOWLEDGEMENTS}

The authors wish to thank T. Yamada and T. Aoki for leading the campaign on Koryto glacier. Thanks also go to S. Yamaguchi, T. Matsumoto and K. Konya for their help with the field measurements. The wire strainmeters were designed and constructed by K. Shinbori at the workshop of the Institute of Low Temperature Science, Hokkaido University. C.F. Raymond kindly provided information about the design and operation of a wire strainmeter. The manuscript was improved by comments from R.S. Anderson, P. Jansson, G.E. Flowers and U.H. Fischer. This study was funded by the Ministry of Education, Science, Sports and Culture, Japan (No. 11691166).

\section{REFERENCES}

Brockmann, M., T. Gasser and E. Herrmann. 1993. Locally adaptive bandwidth choice for kernel regression estimators. J. Amer. Statistical Assoc., 88, 1302-1309.

Glen, J.W. and W.V. Lewis. 1961. Measurements of side-slip at Austerdalsbreen, 1959. J. Glaciol., 3(30), 1109-1122.

Gudmundsson, G.H. 2002. Observations of a reversal in vertical and horizontal strain-rate regime during a motion event on Unteraargletscher, Bernese Alps, Switzerland. J. Glaciol., 48(163), 566-574.

Gudmundsson, G.H., A. Bassi, M. Vonmoos, A. Bauder, U.H. Fischer and M. Funk. 2000. High-resolution measurements of spatial and temporal variations in surface velocities of Unteraargletscher, Bernese Alps, Switzerland. Ann. Glaciol., 31, 63-68.

Hanson, B., R.LeB. Hooke and E.M. Grace, Jr. 1998. Short-term velocity and water-pressure variations down-glacier from a riegel, Storglaciären, Sweden. J. Glaciol., 44(147), 359-367.
Iken, A. and R.A. Bindschadler. 1986. Combined measurements of subglacial water pressure and surface velocity of Findelengletscher, Switzerland: conclusions about drainage system and sliding mechanism. J. Glaciol., 32(110), 101-119.

Iken, A., H. Röthlisberger, A. Flotron and W. Haeberli. 1983. The uplift of Unteraargletscher at the beginning of the melt season a consequence of water storage at the bed? J. Glaciol., 29 (101), 28-47.

Jansson, P. and R.LeB. Hooke. 1989. Short-term variations in strain and surface tilt on Storglaciären, Kebnekaise, northern Sweden. J. Glaciol., 35(120), 201-208.

Kamb, B. and K.A. Echelmeyer. 1986. Stress-gradient coupling in glacier flow: I. Longitudinal averaging of the influence of ice thickness and surface slope. J. Glaciol., 32(111), 267-284.

Mair, D., P. Nienow, I. Willis and M. Sharp. 2001. Spatial patterns of glacier motion during a high-velocity event: Haut Glacier d'Arolla, Switzerland. J. Glaciol., 47(156), 9-20.

Matsumoto, T., R. Naruse, K. Konya, S. Yamaguchi, T. Yamada and Y.D. Murav'yev. 2004. Summer water balance characteristics of Koryto Glacier, Kamchatka Peninsula, Russia. Geogr. Ann., 88A, 169-178.

Naruse, R., H. Fukami and M. Aniya. 1992. Short-term variations in flow velocity of Glaciar Soler, Patagonia, Chile. J. Glaciol., 38(128), 152-156.

Nolan, M. and K. Echelmeyer. 1999. Seismic detection of transient changes beneath Black Rapids Glacier, Alaska, USA: I. Techniques and observations. J. Glaciol., 45(149), 119-131.

Raymond, C.F. and S. Malone. 1986. Propagating strain anomalies during mini-surges of Variegated Glacier, Alaska, USA J. Glaciol., 32(111), 178-191.

Raymond, C.F., R.J. Benedict, W.D. Harrison, K.A. Echelmeyer and M. Sturm. 1995. Hydrological discharges and motion of Fels and Black Rapids Glaciers, Alaska, USA: implications for the structure of their drainage systems. J. Glaciol., 41(138), 290-304.

Shiraiwa, T., Y.D. Murav'yev, S. Yamaguchi, G.E. Glazirin, Y. Kodama and T. Matsumoto. 1997. Glaciological features of Koryto glacier in the Kronotsky Peninsula, Kamchatka, Russia. Bull. Glac. Res., 15, 27-36.

Sugiyama, S. and G.H. Gudmundsson. 2003. Short-term variations in glacier flow controlled by subglacial water pressure at Lauteraargletscher, Bernese Alps, Switzerland. J. Glaciol., 50(170), 353-362.

Yamaguchi, S., R. Naruse, S. Sugiyama, T. Matsumoto and Y.D. Murav'yev. 2003. Initial investigations of dynamics of the maritime Koryto glacier, Kamchatka, Russia. J. Glaciol., 49(165), 173-178. 